\title{
AVALIAÇÃO DA DETECÇÃO DE CONTAMINAÇÃO BACTERIANA EM CONCENTRADOS PLAQUETÁRIOS UTILIZANDO BACTERIOLÓGICO QUANTITATIVO E REDUÇÃO DA CONCENTRAÇÃO DE GLICOSE E DO PH
}

\author{
Rosiéli Martini ${ }^{*}$, Mônica de Abreu Rodrigues ${ }^{* * *}$, Andressa Oss-Emer \\ Soares, Lívia Gindri, Maísa Kraulich Tizotti*, Cláudia Barbisan \\ Kempfer*, Magda Roehrs*, Letícia Eichstaedt Mayer*, Viviane \\ Ratzlaff, Rosmari Horner** \\ Universidade Federal de Santa Maria
}

\begin{abstract}
RESUMO: Introdução: A contaminação bacteriana em concentrados plaquetários (CPs) constitui um problema crítico devido ao risco de eventos sépticos associados à transfusão. A cultura microbiológica dos CPs apresenta alguns desafios como o volume pequeno do inóculo inicial e o tempo para a liberação do resultado. Neste estudo nós avaliamos o desempenho na deteç̧ão da contaminação em 79 amostras de CPs provenientes do Hemocentro do Estado do Rio Grande do Sul de Santa Maria no ano de 2010 por duas diferentes metodologias. Material e Métodos: Cultura bacteriológica quantitativa: semeadura de $100 \mu \mathrm{L}$ de CPs em ágar sangue; e marcadores metabólicos: medida de glicose e pH com tiras reagentes. Resultados: Em todas as análises deste estudo a glicose apresentou valores positivos e $91,13 \%$ ficou com pH acima de 7,5 e $8,87 \%$ abaixo de 7,0 . No $5^{\circ}$ dia $83,55 \%$ das amostras apresentaram glicose negativa. Não houve crescimento bacteriano em nenhuma das amostras que apresentaram $\mathrm{pH}$ inicial ácido. A taxa de contaminação bacteriana foi de 1,27\% (Staphylococcus epidermidis). Conclusão: Concluímos que os marcadores metabólicos utilizados não permitiram a detecção da contaminação bacteriana, uma vez que a amostra positiva não mostrou relação com a acidificação do pH e do consumo da glicose.
\end{abstract}

Descritores: PH; Glicose; Contaminação bacteriana; Concentrados plaquetários; Cultura microbiológica.

\section{EVALUATION OF DETECTION OF BACTERIAL CONTAMINATION IN PLATELET CONCENTRATES USING THE QUANTITATIVE BACTERIOLOGICAL AND REDUCTION THE CONCENTRATION OF GLUCOSE AND PH}

\begin{abstract}
Background: Bacterial contamination in platelet concentrates (PCs) is a critical problem due to the risk of septic events associated with transfusion. The microbiological culture of the PCs present some challenges as the small volume of inoculum and time to release of results. In this study we evaluated the performance in the detection of contamination in 79 samples PCs from the Blood Center of the State of Rio Grande do South of Santa Maria in 2010 by two different methodologies. Methods: Quantitative bacteriological: seeding of $100 \mu \mathrm{L}$ of PCs on blood agar; and metabolic markers: measurements of glucose and $\mathrm{pH}$ by reagent strips. Results: In all analysis of this study the glucose showed positive values and $91.13 \%$ remained above $\mathrm{pH} 7.5$ and $8.87 \%$ below 7.0 . At $5^{\circ}$ day $83.55 \%$ of the samples were negative glucose. There was no bacterial growth in any of the samples with initial $\mathrm{pH}$ acid. The rate of bacterial contamination was $1.27 \%$ Staphylococcus epidermidis). Conclusion: We conclude that metabolic markers used did not allow the detection of bacterial contamination, since the positive sample was not related to the acidification of $\mathrm{pH}$ and consumption of glucose.
\end{abstract}

Descriptors: PH; Glucose; Bacterial contamination; Platelet concentrates; Microbiological culture.

\footnotetext{
* Mestranda do Programa de Pós-Graduação em Ciências Farmacêuticas, Universidade Federal de Santa Maria, Santa Maria, RS.

** Departamento de Análises Clínicas e Toxicológicas, Universidade Federal de Santa Maria, Santa Maria, RS.

${ }^{* * *}$ Acadêmica do Curso de Farmácia, Universidade Federal de Santa Maria, Santa Maria, RS.
} 


\section{Introdução}

Atualmente a infusão de hemocomponentes contaminados por bactérias é uma das principais causas de morbidade e mortalidade entre os receptores. ${ }^{1}$ Este fato representa um considerável problema de saúde pública, especialmente no Brasil.1,2 A contaminação bacteriana pode estar presente em qualquer hemocomponente, principalmente em concentrados plaquetários (CPs), devido à temperatura de armazenamento $\left(20-24^{\circ} \mathrm{C}\right)$ que facilita a proliferação dos microrganismos. Os CPs são os responsáveis pela maior parte dos casos de reações sépticas transfusionais., ${ }^{3,4}$

Vários procedimentos screening são utilizados na rotina pelos bancos de sangue para reduzir os incidentes da contaminação bacteriana de CPs. ${ }^{2,5-8}$ Alguns métodos microbiológicos têm sido efetivos na detecção das bactérias presentes nos CPs, porém com o inconveniente de necessitar um grande intervalo de tempo para a liberação do resultado. Além disso, a maioria destes métodos possui baixa sensibilidade para detectar pequenas quantidades de unidades formadoras de colônia por $\mathrm{mL}$ de sangue (UFC/mL) ${ }^{5,9}$

É de consenso que o crescimento bacteriano provoque uma redução nos níveis de glicose e pH nos líquidos biológicos, como por exemplo, nos CPs. Consequentemente, a diminuição da glicose e dos níveis de pH têm sido amplamente utilizados como indicadores de presença bacteriana. ${ }^{10-14}$ Este teste é um dos métodos sugeridos pela American Association of Blood Banks (AABB), sendo utilizado em vários países. ${ }^{12}$ Entretanto, até o momento, não constatamos nenhum estudo brasileiro que utilizasse esta metodologia com a finalidade de investigar contaminação bacteriana em CPs.

Desta maneira, visto que a transfusão de CPs contaminados com bactérias pode causar reações transfusionais sépticas com desfechos fatais, a prevenção e/ou a redução da ocorrência destas reações constitui um dos maiores desafios enfrentados nos bancos de sangue e na medicina transfusional. ${ }^{15,16}$

Por isso o nosso estudo objetivou investigar a contaminação bacteriana em CPs através de duas metodologias: cultura quantitativa e variação da concentração da glicose e dos níveis de $\mathrm{pH}$ das amostras provenientes do Hemocentro do Estado do Rio Grande do Sul (HEMORGS), de Santa Maria (RS).

\section{Material e métodos}

\section{Coleta e destino das amostras}

Foram analisadas 79 amostras de CPs de até $24 \mathrm{~h}$ as quais foram coletadas no HEMORGS, durante os meses de setembro e outubro de 2010. Não existiram critérios de exclusão, portanto todas as amostras de CPs obtidas nesse período foram incluídas nesta pesquisa.

Estas amostras foram provenientes de dois tipos de coleta: 74 CPs obtidos pela

Saúde (Santa Maria), v.36, n.2, p. 29-38, Avaliação da detecção de contaminação bacteriana em concentrados plaquetários utilizando bacteriológico quantitativo redução da concentração de glicose e do ph 30 centrifugação do sangue total (plaquetas randômicas) e 5 obtidos pelo método de aférese (plaquetaféreses). Os CPs avaliados neste estudo foram coletados a partir da porção tubular das bolsas. Cabe relatar que a porção utilizada neste estudo seria desprezada pelo HEMORGS, não acarretando desperdício de CPs. Após a coleta as amostras foram 
encaminhadas para o Laboratório de Bacteriologia do Departamento de Análises Clínicas e Toxicológicas (DACT) do Centro de Ciências da Saúde (CCS), onde foi efetuado este estudo.

\section{Preparação das amostras}

No laboratório de Bacteriologia as amostras foram manipuladas em cabine de segurança biológica, classe II, tipo B2. A porção tubular da bolsa de plaquetas foi desinfectada com álcool 70\% (friç̧ão por aproximadamente 1 minuto).

As duas metodologias realizadas neste estudo foram:

\section{Semeadura em placa de ágar sangue (AS) de carneiro, com contagem (quantitativa).,2,17,18}

Foram semeados $100 \mu \mathrm{L}$ dos CPs em AS, com o auxílio de pipeta automática, os quais foram incubados a $35^{\circ} \mathrm{C} \pm 2{ }^{\circ} \mathrm{C} 5 \%$ de $\mathrm{CO}_{2}$, por $24-48 \mathrm{~h}$.

A análise do crescimento de colônias bacterianas foi feita nas 24 - 48 h após a semeadura. Nas amostras em que houve crescimento de colônias (positivas) foi efetuada a sua contagem e o resultado relatado foi em UFC/mL, utilizando fator de multiplicação de 10X. Com as amostras positivas foram realizadas, na sequência, coloração de Gram e identificação fenotípica convencional19 e automatizada (MicroScan®-SIEMENS).

\section{Medida do $\mathrm{pH}$ e glicose.10-14}

Aproximadamente $200 \mu \mathrm{L}$ da porção tubular da bolsa de plaquetas, com o auxílio de seringa e agulha estéreis, foram transferidos para um tubo de vidro esterilizado e rosqueado contendo $2 \mathrm{~mL}$ de caldo Mueller Hinton $(\mathrm{CMH})$ e incubados por 5 dias a $35^{\circ} \mathrm{C} \pm 2{ }^{\circ} \mathrm{C}$. A glicose e o pH foram mensurados com o auxílio de tiras reagentes (Biocolor@-Bioeasy) nas primeiras $24 \mathrm{~h}$ após a coleta, em amostra de CPs puro, posterior a adição das plaquetas em $2 \mathrm{~mL}$ do $\mathrm{CMH}$ e na sequência efetuaram-se mais quatro medidas até o quinto dia, com intervalo de $24 \mathrm{~h}$ em cada análise.

Com relação à glicose, nesta pesquisa as amostras foram agrupadas como glicose positiva (faixa de 100 - $2000 \mathrm{mg} / \mathrm{dL}$ ) e glicose negativa (inferior à $50-100 \mathrm{mg} / \mathrm{dL}$ ); em relação ao pH agrupadas em três níveis diferentes: amostras básicas (acima de 7,5), neutras $(7,0$ - 7,5) e ácidas (abaixo de 7,0).

Também foi utilizado um controle negativo constituído apenas de $\mathrm{CMH}$, que foi manipulado da mesma forma que as amostras, com a finalidade de verificar possiveis influências na determinação da glicose e do $\mathrm{pH}$.

\section{Conceitos éticos}

O presente trabalho foi submetido e aprovado pelo Comitê de Ética em Pesquisa (CEP) da Universidade Federal de Santa Maria (UFSM), sob o número 0285.0.243.000-09.

\section{Resultados}

Em 1 das 79 amostras $(1,27 \%)$ houve crescimento bacteriano de incontáveis UFC/mL (método bacteriológico quantitativo), oriunda de $\mathrm{CP}$ randômico. Cocos gram-positivos foram visualizados na microscopia (coloração de Gram), sendo identificados como Staphylococcus epidermidis (metodologia fenotípica convencional e automatizada).

Saúde (Santa Maria), v.36, n.2, p.29-38, jul./dez. 2010

Martini, R.; Rodrigues, M. A.; Soares, A. O; Gindri, L.; Tizotti, M. K.; Kempfer, C. B.; Roehrs, M. C. S. M.; Mayer, L. E; Ratzlaff, V.; Horner, H. ISSN $2236-5843$ 
Nos parâmetros metabólicos concentração de glicose e pH, na metodologia na qual foram utilizadas as fitas de urina, detectamos uma grande variação na concentração da glicose medida no primeiro e no quinto dia. Em todas as amostras analisadas neste estudo, a glicose apresentou-se positiva, quando medida na plaqueta pura. No primeiro dia, quando a plaqueta foi semeada no $\mathrm{CMH}, 92,41 \%$ mostrou-se positiva. $62,03 \%$ das amostras no segundo dia foram negativas. No quarto e quinto dias em aproximadamente $84 \%$ das amostras a glicose foi negativa (Gráfico 1).

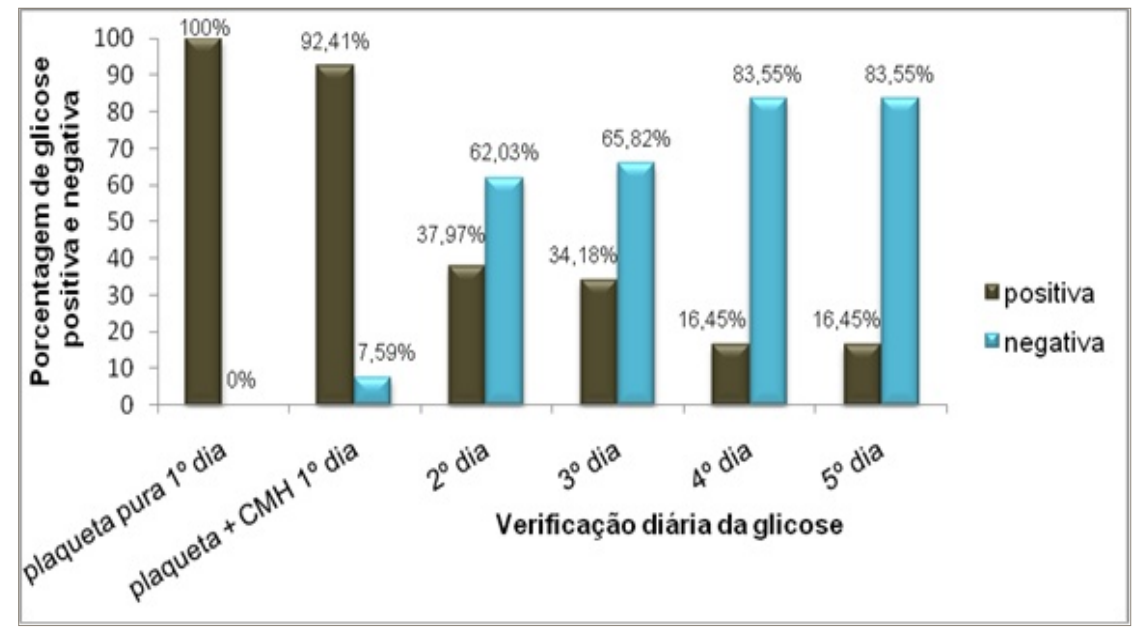

Gráfico 1 - Relação da porcentagem positiva ou negativa dos níveis de glicose de todas as amostras analisadas durante a realização diária das suas medidas.

A amostra que apresentou crescimento bacteriano foi glicose positiva no primeiro dia (500 $\mathrm{mg} / \mathrm{dL}$ ). Nos segundo, terceiro, quarto e quinto dias a amostra positiva permaneceu com glicose positiva (100 mg/dL). O controle negativo, composto apenas de $\mathrm{CMH}$, mostrou-se negativo durante todas as medidas (primeiro ao quinto dia).

$\mathrm{O}$ pH apresentou oscilação nos seus valores, em todas as amostras analisadas (Gráfico 2). No primiero dia, $8,86 \%$ das amostras (7 de 79 ) tiveram pH ácido (plaqueta pura sem $\mathrm{CMH}$ ). A amostra na qual foi isolado o $\mathrm{S}$. epidermidis, teve $\mathrm{pH}$ neutro na plaqueta pura e no $\mathrm{CMH}$ no primeiro dia. No segundo dia apresentou-se pH neutro e nos demais dias, pH básico $(8,0)$. Além disso, algumas amostras isentas de microrganismos que inicialmente eram neutras ou básicas tornaram-se ácidas no final da análise.

Saúde (Santa Maria), v.36, n.2, p. 29-38, jul./dez. 2010. Avaliação da detecção de contaminação bacteriana em concentrados plaquetários utilizando bacteriológico quantitativo e redução da concentração de glicose e do ph

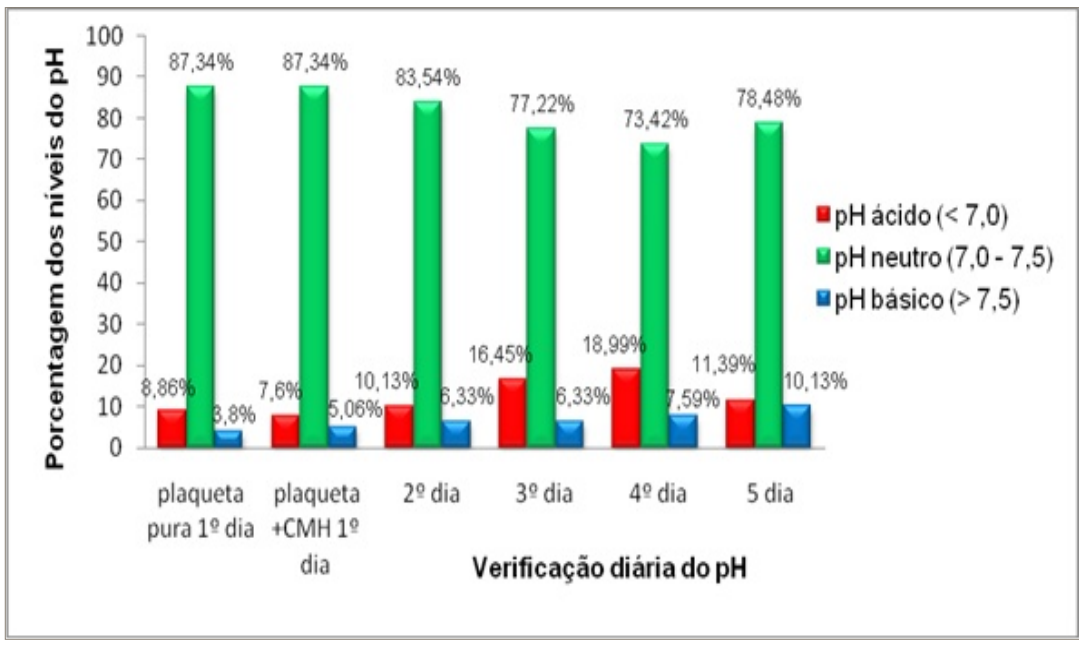

Gráfico 2 - Relação da porcentagem dos níveis de pH de todas as amostras durante a realização diária das suas medidas. 


\section{Discussão}

A contaminação bacteriana das plaquetas constitui o risco de infecção mais comum das transfusões. A presença de bactérias contaminantes em plaquetas pode desencadear eventos sépticos. Os receptores destes CPs transfundidos normalmente são pacientes imunossuprimidos e, portanto mais suscetíveis a infecções bacterianas. ${ }^{4}$

Atualmente, devido à emergência de episódios de sepse após transfusões de plaquetas, os serviços de hemoterapia juntamente com os órgãos responsáveis pelo controle de qualidade vêm buscando desenvolver e aprimorar técnicas eficientes, práticas e mais rápidas que as bacteriológicas na detecção de bactérias em componentes sanguíneos.

A cultura bacteriana é claramente 0 método atual de escolha para a detecção da contaminação bacteriana em plaquetas obtidas por aférese (único doador), porém, este método não tem sido prático para a avaliação dos CPs randômicos. ${ }^{14} \mathrm{O}$ que pode tornar 0 método de cultura microbiológica não realizável numa rotina de banco de sangue, onde há uma grande escala de produção de CPs derivados de sangue total, é devido à elevada mão de obra que depende da quantidade de CPs produzidos e pelo intervalo de tempo necessário para o crescimento bacteriano, diferentemente das amostras de plaquetaféreses, as quais são de baixa produção e direcionadas a determinados pacientes. Por esta razão, desde 2004 a AABB permitiu o uso de técnicas alternativas para a detecção de bactérias. Esta associação permite incluir o uso da coloração bacteriana (Gram) e de fitas de urina multi-reagentes para detectar a redução da concentração de glicose e pH causada pelo crescimento bacteriano. ${ }^{12}$ Além do mais, nos países acreditados pelo Food and Drug Administration (FDA), a análise microbiológica é preconizada em todas as amostras de plaquetas. ${ }^{12}$

Já no Brasil, a Resolução da Diretoria Colegiada (RDC) n 153, de 14 de junho de 2004 estabelece que 0 controle microbiológico seja realizado em apenas $1 \%$ das bolsas produzidas ou em 10 amostras aleatórias por mês; a escolha deve ser em relação a que apresentar maior número de amostras ${ }^{20}$ Esta nossa RDC não preconiza a execução da triagem em toda a produção mensal e não descreve a metodologia de cultura preconizada para este fim..$^{20}$

A prevalência da contaminação bacteriana neste estudo foi de 1,27\% (1 de 79), semelhante ao estudo anterior por nós realizado no ano de 2009 e início de 2010, no qual detectamos $1,7 \%$ (5 de 292) de contaminação nos CPs do HEMORGS. ${ }^{2}$ Já Cunha e cols (2006) detectaram uma contaminação menor em CPs, de 0,4\% (8 de 2000), em estudo realizado em Goiânia (BRA). ${ }^{1}$

A taxa de contaminação encontrada em nosso estudo, também quando comparada com pesquisas realizadas fora do Brasil, se encontra um pouco maior aos estudos de WaltherWenke e cols (2010) que encontraram um valor de 0,3\% de culturas contaminadas de CPs (169 de 52.243), estudo realizado em centros da Cruz Vermelha na Alemanha. ${ }^{21} \mathrm{E}$ em outra pesquisa efetuada na Fundação do serviço de doação de sangue em Taiwan, Hsueh e cols (2009) obtiveram 0,34\% (8 de 2.338) de contaminação em CPs. ${ }^{22}$

No entanto, quando compararmos a prevalência de contaminação deste estudo com o descrito por Cunningham e cols (1973), realizado em um centro de transfusão no sudeste da Escócia, nossos valores se encontraram 5 vezes inferior a contaminação relatada $\left(6,3 \%=63\right.$ de 1000). ${ }^{23}$

No que se refere aos marcadores metabólicos utilizados, a redução da concentração da glicose a limites não detectáveis, em $62,03 \%$ das amostras no segundo dia da análise, e de aproximadamente $84 \%$ no final do quarto e quinto dias, poderia sugerir a contaminação das

Saúde (Santa Maria), v.36, n.2, p.29-38, jul./dez. 2010

Martini, R.; Rodrigues, M. A.; Soares, A. O.; Gindri, L.; Tizotti, M. K.; Kempfer, C. B.; Roehrs, M. C. S. M.; Mayer, L. E; Ratzlaff, V.; Horner, H. \begin{tabular}{l|l} 
ISSN $2236-5843$ & 33
\end{tabular} 
mesmas. Portanto, não foi possível estabelecer nenhuma relação da variação da glicose com a presença de bactérias nos CPs, já que a negativação da glicose $(83,55 \%)$ ocorreu numa taxa aproximadamente 66 vezes superior a prevalência bacteriana encontrada neste estudo $(1,27 \%)$ não sendo um indicativo de contaminação bacteriana dos CPs. A redução do pH também não mostrou ser um parâmetro confiável na mesma detecção, uma vez que iniciou com 8,86\% (7 das 79) das amostras com pH ácido; teve o maior pico no quarto dia, com $18,99 \%$ das amostras com este $\mathrm{pH}$ e baixando para $11,39 \%$ no quinto dia. Além do mais, a amostra em que foi isolado os $\mathrm{S}$. epidermidis na cultura, não apresentou pH ácido.

Quando comparamos a metodologia do $\mathrm{pH}$ e da glicose com a cultura quantitativa, nossos resultados não demonstraram nenhuma relação da diminuição do pH e do consumo da glicose com a presença de bactéria na amostra de plaquetas analisada, estando em conformidade com o estudo realizado por Myhre e cols (1985) o qual também verificou que 0 pH pode diminuir, permanecer inalterado, ou, em alguns casos, até aumentar nas amostras com crescimento bacteriano. ${ }^{24}$ Também está de acordo com demais estudos descritos na literatura internacional, como o executado por Tarrand e cols (2004) na Universidade do Texas (EUA) que afirma que as tiras reagentes são consistentemente insensiveis para detectar contaminação por $\mathrm{S}$. epidermidis em plaquetas. ${ }^{25}$

Estudo feito por Clark e cols (2006) na Universidade do Sistema de Saúde da Virgínia (EUA), também compararam os resultados da cultura com o pH e a glicose, e concluíram que as fitas reagentes não identificaram nenhuma amostra que foi positiva pela cultura microbiológica. ${ }^{14} \mathrm{Na}$ pesquisa realizada por Werch e cols (2002) na Universidade do Texas (EUA), somente 2 de 30 CPs contaminados foram detectados pelas fitas reagentes, correlacionando-se pobremente com a contaminação bacteriana, demonstrando assim um baixo valor preditivo positivo. ${ }^{11}$

Wagner e cols (1996) na Cruz Vermelha Americana (EUA) e Burstain e cols (1997) na Universidade da Carolina do Norte (EUA), também alertam que para as fitas detectarem a contaminação bacteriana por estes dois parâmetros são necessárias altas taxas de UFC/mL, em torno de $10^{7} \mathrm{UFC} / \mathrm{mL}$, o que demonstra sua baixa sensibilidade. ${ }^{10,26}$ Entretanto, Burstain e cols (1997) afirmam que as tiras reagentes podem ser utilizadas de forma rápida e barata para a detecção de contaminação bacteriana em $\mathrm{CPs}^{26}$ Isto é devido que estes testes são considerados simples, rápidos e de baixo custo, porém, podem apresentar uma altíssima taxa de falsos-positivos. ${ }^{27}$

Os nossos resultados nos permitem concordar com a conclusão de Clark e cols (2006), 0 qual descreve que nenhuma técnica alternativa, que não a bacteriológica, para a detecção da contaminação bacteriana em CPs é efetiva. ${ }^{14}$ Yomtovian e cols (1993) em um estudo efetuado na Universidade da Reserva de Case Western (EUA), e a AABB (2004) relatam que 0 bacteriológico detecta bactérias à níveis de $10^{2} \mathrm{UFC} / \mathrm{mL}$ e o bacterioscópico somente quando os níveis estão em $10^{4}-10^{6} \mathrm{UFC} / \mathrm{mL} .^{12,28}$ Além disso, a coloração ainda depende da prática do operador para a liberação do resultado, representando, portanto, uma análise não facilmente incorporável da rotina diária. ${ }^{14}$

Com as amostras ensaiadas neste estudo, não houve correlação entre as duas

Saúde (Santa Maria), v.36, n.2, p. 29-38, jul./dez. 2010. Avaliação da detecção de contaminação bacteriana em concentrados plaquetários utilizando bacteriológico quantitativo e redução da concentração de glicose e do ph 34

ISSN 2236-5834 metodologias utilizadas na deteç̧ão da contaminação bacteriana dos CPs. Este estudo foi uma tentativa de avaliar o desempenho de uma nova metodologia (marcadores metabólicos) para investigar este tipo de contaminação, método já referido na literatura internacional destacando-se por sua facilidade na execução, pelo curto intervalo de tempo e por seu custo acessível. 
Na prática, a mudança da cor da fita reagente na detecção do pH e concentração de glicose poderia representar uma metodologia rápida e de fácil interpretação por qualquer operador na rotina dos hemocentros, diferentemente das dificuldades na leitura do método que usa a coloração de Gram e/ou da cultura, a qual necessita de mais tempo para a liberação. No entanto, nossos resultados demonstraram ser este método não específico e pouco confiável para detectar bactérias em plaquetas.

\section{Conclusão}

Mesmo que haja melhorias no que se refere ao procedimento anterior à coleta, como por exemplo, na assepsia do local da punção, no questionário de triagem, na realização completa do leucograma e entre outros, no Brasil, permanece a necessidade de buscarmos aprimoramento das técnicas existentes e 0 uso de métodos automatizados para a deteç̧ão de contaminantes bacterianos principalmente em plaquetas. Destaca-se, em especial o Bact/Alert, o qual é considerado um sistema de detecção microbiana com tecnologia de ponta, destacando-se por sua alta sensibilidade e especificidade, rapidez e exatidão na obtenção dos resultados e além do mais por $95 \%$ de recuperação de microrganismos em até 24 horas. Só assim, será possivel garantirmos maior segurança nas transfusões sanguíneas, já que os pacientes são únicos em suas necessidades.

\section{Referências Bibliográficas}

1. Cunha Júnior GS. Prevalência da contaminação bacteriana em concentrados de plaquetas do serviço de hemoterapia de um hospital universitário em Goiânia-GO. 2006. 75 f. Dissertação (Mestrado em Medicina Tropical) - Universidade Federal de Goiás, Goiânia, 2006.

2. Martini R, et al. Contaminação bacteriana em concentrados plaquetários: identificação, perfil de sensibilidade aos antimicrobianos e sepse associada à transfusão. Revista da Sociedade Brasileira de Medicina Tropical 2010; 43: 682-685.

3. Goldman M, Blajchman MA. Blood product-associated bacterial sepsis. Transfus Med Rev 1991; 5: 73-83.

4. Blajchman MA, Goldman M. Bacterial contamination of platelet concentrates: incidence, significance, and prevention. Semin Hematol 2001; 38: 20-26.

5. Mitchell KMT, Brecher ME. Approaches to the detection of bacterial contamination in cellular blood products. Transfus Med Rev 1999; 13: 132-44.

6. Pietersz RNI, Engelfriet CP, Reesink HW. Detection of bacterial contamination of platelet concentrates. Vox Sang 2003; 85: 224-239.

7. Morel $P$, Deschaseaux $M$, Bertrand $X$, Naegelen, Talon $D$. Transfusion et bactéries: risque résiduel et perspectives de prévention. Transfus Clin Biol 2003; 10: 192-200.

8. Blajchman MA, Goldman M, Baeza F. Improving the bacteriological safety of platelet transfusion. Transfus Med Rev 2004; 18: 11-24.

Saúde (Santa Maria), v.36, n.2, p.29-38, jul./dez. 2010

9. Murphy WG, Smyth J. Testing for bacteria in platelet concentrates: defining the parameters. Transfus Apher Sci 2001; 24: 247-249.

Martini, R.; Rodrigues, M. A.; Soares, A. O. Gindri, L.; Tizotti, M. K.; Kempfer, C. B.; Roehrs, M. C. S. M.; Mayer, L. E; Ratzlaff, V.; Horner, H. 
10. Wagner SJ, Robinette D. Evaluation of swirling, $\mathrm{pH}$, and glucose tests for the detection of bacterial contamination in platelet concentrates. Transfusion 1996; 36: 989-993.

11. Werch JB, Mhawech P, Stager CE, Banez El, Lichtiger B. Detecting bacteria in platelet concentrates by use of reagent strips. Transfusion 2002; 42: 1027-1031.

12. American Association of Blood Banks Standards for Blood Banks and Transfusion Services, 23rd ed, AABB, Bethesda, 2004, Section 5.1.5.1, p 11.

13. Hay SN, Brecher ME. Validation of $\mathrm{pH}$ and glucose determination for bacteria detection screening in platelet concentrates stored in the Terumo Teruflex XT612 platelet container. Transfusion 2004; 44: 1395.

14. Clark P, Parsons TM, Boyd JC, Dewey P, Mintz PD. Imported Platelets Demonstrate Decreased pH and Glucose by Reagent Strip Testing when Compared to Locally Derived Platelets. Annals of Clinical \& Laboratory Science 2006; 36: 443-446.

15. Depcik-Smith ND, Hay SN, Brecher ME. Bacterial contamination of blood products: factors, options, and insights. J Clin Apher 2001; 16: 192-201.

16. Kopko PM, Holland PV. Mechanisms of severe transfusion reactions. Transfus Clin Biol 2001; 8: 278-281.

17. Guerin GD, Burter LP. Avaliação de Concentrados Plaquetários produzidos pelo serviço de Hemoterapia de Hospital de Santo Ângelo: implantação de um sistema de controle de qualidade. Rev Bras Anal Clin 2006; 38 : 287-92.

18. Yomtovian RA, et al. Evolution of surveillance methods for detection of bacterial contamination of platelets in a university hospital, 1991 through 2004. Transfusion 2006; 46: 719-730.

19. Koneman EW, Stephen AD, Janda WM, Schreckenberger PC, Winn WC. Diagnóstico Microbiológico. Texto e Atlas Colorido. $6^{\mathrm{a}}$ ed. Rio de Janeiro: Guanabara-Koogan; 2008.

20. Ministério da Saúde. Agência Nacional de Vigilância Sanitária (ANVISA). Resolução 153 de 13 de junho de 2004. Determina o Regulamento Técnico para os procedimentos hemoterápicos, incluindo a coleta, 0 processamento, a testagem, o armazenamento, o transporte, o controle de qualidade e o uso humano de sangue, e seus componentes, obtidos do sangue venoso, do Cordão umbilical, da placenta e da medula óssea. Di'srio Oficial da União, Brasília, DF, 24 de Junho; Seção 1, 2004. p. 68.

21. Walther-Wenke $G$, et al. Screening of platelet concentrates for bacterial contamination: spectrum of bacteria detected, proportion of transfused units, and clinical follow-up. Ann Hematol 2010; 89: 83-91.

22. Hsueh JC, et al. Blood surveillance and detection on platelet bacterial contamination associated with septic events. Transfus Med 2009; 19:350-356.

23. Cunningham M, Cash JD. Bacterial contamination of platelet concentrates stored at $20^{\circ} \mathrm{C}$. J Clin Pathol 1973; 26: 401-404.

24. Myhre BA, Demianew SH, Yoshimori RN, Nelson EJ, Carmen RA. pH changes caused by bacterial growth in contaminated platelet concentrates. Ann Clin Lab Sci 1985; 15: 509-514.

25. Tarrand J, Sazama KJ, Lichtiger B. Reagent Strips May Not Detect Staphylococcus epidermidis Contamination of Platelet Concentrates. Arch Pathol Lab Med 2004; 128: 852-853.

26. Burstain JM, Brecher ME, Workman K, Foster M, Faber GH, Mair D. Rapid identification of bacterially contaminated platelets using reagent strips: glucose and $\mathrm{pH}$ analysis as markers of bacterial metabolism. Transfusion 1997; 37: 255-258.

27. Byrne KM, Grose LH, Renoud, KJ. Detecting Platelet Contamination: It's in the Bag. Transfusion therapy is plagued by an onslaught of viral pathogens. ADVANCE for Medical Laboratory Professionals 2004; 16:18.

Saúde (Santa Maria), v.36, n.2, p. 29-38, jul./dez. 2010. Avaliação da detecção de contaminação bacteriana em concentrados plaquetários utilizando bacteriológico quantitativo e redução da concentração de glicose e do ph
28. Yomtovian R, Lazarus HM, Goodnough LT, Hirschler AM, Morrissey AM, Jacobs MR. A prospective microbiologic surveillance program to detect and prevent the transfusion of bacterially contaminated platelets. Transfusion 1993; 33: 902-909. 
Rosiéli Martini - Rua Floriano Peixoto 1321 ap 202, Centro, Santa Maria, Rio Grande do Sul, Brasil. Telefone: (55)30251275

E-mail: rosifarma@gmail.com

Recebido em 31 de janeiro de 2011.

Aprovado em 07 de abril de 2011.

Martini, R.; Rodrigues, M. A.; Soares, A. O.; Gindri, L.; Tizotti, M. K.; Kempfer, C. B.; Roehrs, M. C. S. M.; Mayer, L. E; Ratzlaff, V.; Horner, H. 